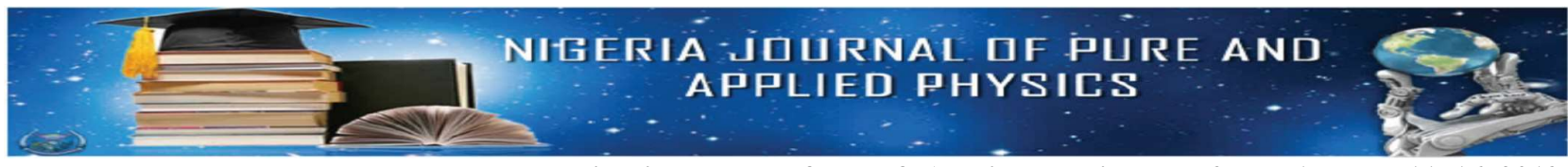

Nigeria Journal of Pure \& Applied Physics, Vol. 9, No. 1, pages 11-16, 2019

\title{
Thermodynamic Prediction of the Free Energy of Mixing and Activities of some Gold- based Binary Liquid Alloys
}

\author{
Y. A. Odusote ${ }^{\dagger}$, A. I. Popoola \\ Condensed Matter Research Group, Department of Physics, Federal University of Technology Akure, Nigeria. \\ ${ }^{\dagger}$ Corresponding Author’s Email: yaodusote@futa.edu.ng yisau24@yahoo.co.uk
}

\begin{abstract}
The free energy of mixing and activities of gold in selected six Au-based binary liquid $\mathrm{Au}-\mathrm{Cu}, \mathrm{Au}-\mathrm{Zn}, \mathrm{Au}-\mathrm{Pb}, \mathrm{Au}-\mathrm{Ni}, \mathrm{Au}-\mathrm{Sn}$ and $\mathrm{Al}-\mathrm{Au}$ alloys at different working temperatures have been studied using the quasi-chemical approximation model (QCAM). The predicted free enegry of mixing and activities results were compared with available experimental values. The predicted results are in reasonable agreement with reported experimental data and confirms that the model is reliable and, thus should serve as an alternative for the prediction of thermodynamic properties of binary liquid alloys.
\end{abstract}

Keywords: free energy of mixing, activities, Au, Binary liquid alloys, concentration

\section{INTRODUCTION}

Lack of sufficient thermodynamic data especially on the free energy of mixing and activity data has been identified as a great challenge in the field of liquid alloy developments. Although some

experimental investigations have been carried out [1-7] Still, there exists quantitative data gaps for the multicomponent liquid alloys due to the difficulties associated with high-temperature experiments. More so that evidences have shown that the binary and other multi-component systems may have better properties for industrial processes, it is therefore obviously unrealistic to rely solely on the experiments for all relevant data. To compliment experimental efforts and fill the needed data gaps, the scientific community has over the years relied on modelling [8-12].

For this purpose, many theories or thermodynamic models that attempts to explain reasonably the change of activity coefficient with concentration for binary and multicomponent liquid alloys have been proposed [8-9, 13-15]. Despite the success of these models, it is however, limited in most cases for estimating large quantities of thermodynamic data directly. The heat of formation model for binary alloys by Miedema and co-workers [16-17] is a very important achievement in this regard. The model allows the calculation of heat of formation of almost all binary alloys on the basis of properties such as molar volume $\mathrm{V}$, electronegativity $\varnothing$, and electron density, $\mathrm{n}_{\mathrm{ws}}$, of elements in the systems. The quasi-chemical approximation model (QCAM) [18] or any of the other numerous available models have been employed by researchers [1923 ] to explain the concentration dependent thermodynamic properties of binary liquid alloys. In the model formulations, the deviation of the properties of an alloy from the ideal mixing behaviour is gauged in terms of the interatomic interactions and the energy of the bonds between the constituent species. The information on the energetic and the structure of melts as well as the ways they are coupled are important factors in understanding the alloying behaviour in binary liquid alloys.

From the viewpoint of theoretical modelling, all binary liquid alloys may be broadly grouped into two major categories: short-range ordered or segregating alloys. The categorization is based on the deviation of the mixing properties from ideal mixture behaviour. In terms of energetic and structure, the first group is characterized by a strong interactive tendency between unlike atoms and by the formation of hetero-paired atoms. On the other hand, the second category is one in which the attractive force between like atoms is much greater than between unlike atoms, and the formation of homo-paired atoms takes place [18, 24-25].

The purpose of this work is to apply the QCAM to predict the thermodynamic properties i.e. the free energy of mixing and activity of some selected gold-based binary alloys. These two thermodynamic properties are cardinal in understanding the separation mechanism in metallurgical process [26]. It is important to note that existence of reliable and consistent thermodynamic databases on binary liquid systems is crucial for the reliable modelling of thermodynamic properties of higher component systems such as ternary $\mathrm{Au}-\mathrm{Sb}-\mathrm{Sn}$ and quaternary $\mathrm{Au}-\mathrm{Sb}-\mathrm{Sn}-\mathrm{Cu}$, which relies on accurate data of their constitutive binary systems. In order to further establish the reliability of the QACM in predicting thermodynamic properties, the free energy of mixing of binary liquid Ti-Si alloys at $2000 \mathrm{~K}$, $2400 \mathrm{~K}$ and $2473 \mathrm{~K}$, respectively were also calculated and compared with the experimental data of Kostov et al. [10].

The motivation for selecting gold-based binary liquid $\mathrm{Au}-\mathrm{Cu}, \mathrm{Au}-\mathrm{Zn}, \mathrm{Au}-\mathrm{Pb}, \mathrm{Au}-\mathrm{Ni}, \mathrm{Au}-\mathrm{Sn}$ and $\mathrm{Al}-\mathrm{Au}$ alloys for investigation are borne out of the fact that gold and its 
constituent alloying elements have attracted a lot of attention in recent times due to their diverse commercial and industrial values [27-28]. For instance, gold is particularly relevant for both fundamental and applied research. In the bulk form, gold is the most inert and softest metal [29]. Apart from its commercial value, the unique chemical and physical properties offered by gold are increasingly being investigated in a growing number of applications. These include uses within the fields of nanotechnology and medicine for products such as smartcards, automotive electronics, sensors, medical implants and drug delivery systems.

The rest of the manuscript is organized as follows: the theoretical formulation of the QCAM is given in the next section, followed by results and discussion. Finally, the conclusions are provided in the last section.

\section{QUASI-CHEMICAL APPROXIMATION MODEL (QCAM) FORMULATION}

If the grand partition function $\Xi$ of a binary liquid A-B alloy containing $N_{A}=N c$ and $N_{B}=N(1-c)$ atoms of elements $\mathrm{A}$ and $\mathrm{B}$, respectively, is expressed as:

$\Xi=\sum_{E} q_{A}^{N_{A}}(T) q_{B}^{N_{B}}(T) \exp \left[\mu_{A} N_{A}-\mu_{B} N_{B}-E\right) / k_{B} T$

where the total number of atoms, $\mathrm{N}=N_{A}+N_{B} . k_{B}$ is the Boltzmann's constant, $\mathrm{T}$ is the absolute temperature and $\mathrm{E}$ is the configurational energy of the alloy. The quantities $q_{i}^{N}(T)$ and $\mu_{i}$ are atomic partition function and chemical potential of $i^{t h}$ components $(i=A, B)$, respectively.

The solution of Eqn. (1) is given as the ratio of the activity coefficient of alloy components, $\gamma,\left(\gamma=\gamma_{\mathrm{A}} / \gamma_{\text {в }}\right)$, after some algebraic simplifications [30-31]:

Table 1: Fitted values of the interaction parameters for the binary liquid alloys.

\begin{tabular}{|c|c|c|c|}
\hline Alloys & $\mathbf{T}(\mathbf{K})$ & $\mathbf{Z}$ & $\boldsymbol{\omega}(\boldsymbol{e V})$ \\
\hline $\mathrm{Au}-\mathrm{Cu}$ & 1550 & 10 & -0.2467 \\
\hline $\mathrm{Au}-\mathrm{Zn}$ & 1080 & 10 & -0.7042 \\
\hline $\mathrm{Au}-\mathrm{Pb}$ & 1200 & 10 & -0.1218 \\
\hline $\mathrm{Au}-\mathrm{Ni}$ & 1150 & 10 & 0.1825 \\
\hline $\mathrm{Au}-\mathrm{Sn}$ & 823 & 10 & -0.4562 \\
\hline $\mathrm{Al}-\mathrm{Au}$ & 1338 & 10 & -1.1322 \\
\hline $\mathrm{Ti}-\mathrm{Si}$ & 2000 & 10 & -1.6260 \\
\hline $\mathrm{Ti}-\mathrm{Si}$ & 2400 & 10 & -1.5723 \\
\hline $\mathrm{Ti}-\mathrm{Si}$ & 2473 & 10 & -1.5567 \\
\hline
\end{tabular}

$$
\ln \gamma=\frac{Z(1-c)}{2 c} \cdot \frac{(\beta+2 c-1)}{(\beta-2 c+1)}
$$

with $\beta=\left\{1+4 c(1-c)\left(\eta^{2}-1\right)\right\}^{1 / 2}$

$$
\begin{aligned}
& \eta^{2}=\exp \left(\frac{2 \omega}{z k_{B} T}\right) ; \\
& \omega=Z\left[\Delta \varepsilon_{A B}-\frac{1}{2}\left(\Delta \varepsilon_{A A}+\Delta \varepsilon_{B B}\right)\right]
\end{aligned}
$$

The quantity $\omega$ in Eqn. (4) is the interchange or ordered energy, while $\Delta \epsilon_{A B}, \Delta \epsilon_{A A}, \Delta \epsilon_{B B}$ are the interaction energy parameters. $\Delta \epsilon_{i j}$ is the change in the energy of the $i j$ bond in the complex $A_{\mu} B_{v}, \mathrm{Z}$ is the coordination number, $\mathrm{c}$ is the concentration of atom $\mathrm{A}$ and $\mathrm{R}$ is the universal gas constant. Using standard thermodynamic relations [32], the Gibbs free energy of mixing $G_{M}$ is obtained from Eqn. (2) as:

$$
\begin{aligned}
& G_{M}=R T\left\{c \ln c+c(1-c) \ln (1-c)+c \ln \gamma_{A}+(1-\right. \\
& \text { c) } \left.\ln \gamma_{B}\right\} \\
& \text { with } \\
& \gamma_{A}=\left\{\frac{\beta-1+2 c}{c(1+\beta}\right\}^{Z / 2} \\
& \gamma_{B}=\left\{\frac{\beta+1-2 c}{(1-c)(1+\beta}\right\}^{Z / 2}
\end{aligned}
$$

here $\gamma_{A}$ and $\gamma_{B}$ are activity coefficients of atoms $\mathrm{A}$ and $\mathrm{B}$, respectively. The activities of the components in a binary liquid alloy are given by:

$a_{i}=c \gamma_{i} \quad ; \quad(i=A, B)$

\begin{tabular}{|c|c|c|c|c|}
\hline & \multicolumn{4}{|c|}{$\mathbf{A u}-\mathbf{C u}$} \\
\hline $\mathrm{C} A \boldsymbol{u}$ & $\mathbf{G}_{\mathbf{M}} / \mathbf{R T}^{(\text {Pre.) }}$ & $\mathbf{G}_{\mathbf{M}} / \mathbf{R T}^{\text {(Expt.*) }}$ & $\mathbf{a}_{\mathrm{Au}}{ }^{\text {(Pre. })}$ & $\mathbf{a}_{\mathrm{Au}}{ }^{\text {(Expt.* })}$ \\
\hline 0.1 & -0.49387 & -0.49504 & 0.021 & 0.022 \\
\hline 0.2 & -0.80427 & -0.80204 & 0.058 & 0.061 \\
\hline 0.3 & -1.01346 & -1.00671 & 0.115 & 0.120 \\
\hline 0.4 & -1.13583 & -1.12534 & 0.198 & 0.240 \\
\hline 0.5 & -1.17620 & -1.16412 & 0.308 & 0.314 \\
\hline 0.6 & -1.13583 & -1.12534 & 0.444 & 0.445 \\
\hline 0.7 & -1.01346 & -1.00671 & 0.595 & 0.592 \\
\hline 0.8 & -0.80427 & -0.80204 & 0.746 & 0.742 \\
\hline 0.9 & -0.49387 & -0.49504 & 0.885 & 0.883 \\
\hline
\end{tabular}

The standard error is computed by:

$S_{i}= \pm\left[\sum^{\left(a_{i} i_{, \text {pre }}{ }^{2}, \exp /\right.}{ }_{n}[]^{1 / 2}\right]$

Table 2: Predicted and Experimental free energy of mixing values along with the calculated activity of $\mathrm{Au}$ in binary liquid $\mathrm{Au}-\mathrm{Cu}$ alloys at $1550 \mathrm{~K}$, respectively [1]. $\quad\left(S_{G_{M}}= \pm 0.0072 \quad S_{a_{A u}}= \pm 0.0145\right)$ 
Table 3: Predicted and Experimental free energy of mixing values along with the calculated activity of $\mathrm{Au}$ in binary liquid $\mathrm{Au}-\mathrm{Zn}$ alloys at 1080 $\mathrm{K}$, respectively [1]. $\left(S_{G_{M}}= \pm 0.2560, S_{a_{A u}}= \pm 0.0720\right)$

\begin{tabular}{|c|c|c|c|c|}
\hline & \multicolumn{4}{|c|}{ Au-Zn } \\
\hline $\mathrm{C} A \boldsymbol{u}$ & $\mathbf{G}_{\mathbf{M}} / \mathbf{R T}^{(\text {Pre.) }}$ & $\mathbf{G}_{\mathbf{M}} / \mathbf{R T}^{\left(\text {Expt. }{ }^{*}\right)}$ & $\mathbf{a}_{\mathrm{Au}}{ }^{\text {(Pre.) }}$ & $\mathbf{a}_{\mathrm{Au}}{ }^{(\text {Expt. } *)}$ \\
\hline 0.1 & -1.03948 & -1.78672 & 0.0001 & 0.0001 \\
\hline 0.2 & -1.82901 & -1.93359 & 0.0006 & 0.0006 \\
\hline 0.3 & -2.42389 & -2.52012 & 0.0028 & 0.0026 \\
\hline 0.4 & -2.80293 & -2.87139 & 0.0127 & 0.0117 \\
\hline 0.5 & -2.93450 & -2.98925 & 0.0531 & 0.0485 \\
\hline 0.6 & -2.80293 & -2.84847 & 0.1721 & 0.1470 \\
\hline 0.7 & -2.42389 & -2.45604 & 0.3871 & 0.3280 \\
\hline 0.8 & -1.82901 & -1.84846 & 0.6430 & 0.5980 \\
\hline 0.9 & -1.03948 & -1.04491 & 0.8592 & 0.6580 \\
\hline
\end{tabular}

Table 4: Predicted and Experimental free energy of mixing values along with the calculated activity of $\mathrm{Au}$ in binary liquid $\mathrm{Au}-\mathrm{Pb}$ alloys at 1200 $\mathrm{K}$, respectively [1]. ( $\left.S_{G_{M}}= \pm 0.0212, S_{a_{A u}}= \pm 0.0137\right)$

\begin{tabular}{|c|c|c|c|c|}
\hline & \multicolumn{4}{|c|}{$\mathbf{A u}-\mathbf{P b}$} \\
\hline $\mathrm{CAu}$ & $\mathbf{G}_{\mathbf{M}} / \mathbf{R T}^{\text {(Pre. }}$ & $\mathbf{G}_{\mathbf{M}} / \mathbf{R T}^{(\text {Expt.*) }}$ & $\mathbf{a}_{\mathrm{Au}}{ }^{\text {(Pre. })}$ & $\begin{array}{c}\mathbf{a}_{\mathrm{Au}}{ }_{*} \text { (Expt. } \\
\end{array}$ \\
\hline 0.1 & -0.43216 & -0.45756 & 0.038 & 0.039 \\
\hline 0.2 & -0.69232 & -0.69549 & 0.092 & 0.103 \\
\hline 0.3 & -0.86426 & -0.86021 & 0.165 & 0.179 \\
\hline 0.4 & -0.96367 & -0.95173 & 0.258 & 0.261 \\
\hline 0.5 & -0.99629 & -0.97003 & 0.369 & 0.368 \\
\hline 0.6 & -0.96367 & -0.92427 & 0.495 & 0.472 \\
\hline 0.7 & -0.86426 & -0.84191 & 0.630 & 0.608 \\
\hline 0.8 & -0.69232 & -0.67719 & 0.764 & 0.750 \\
\hline 0.9 & -0.43216 & -0.44841 & 0.890 & 0.880 \\
\hline
\end{tabular}

Table 5: Predicted and Experimental free energy of mixing values along with the calculated activity of $\mathrm{Au}$ in binary liquid Au-Ni alloys at $1150 \mathrm{~K}$, respectively [1]. ( $S_{G_{M}}= \pm 0.0308$, $\left.S_{a_{A u}}= \pm 0.0624\right)$

\begin{tabular}{|c|c|c|c|c|}
\hline & \multicolumn{2}{|c|}{ Au-Sn } & & \\
\hline $\mathrm{C} A u$ & $\mathbf{G M}_{\mathrm{M}} / \mathbf{R T}^{(\text {Pre. })}$ & $\mathbf{G}_{M} / \mathbf{R T}^{\text {(Expt.* }}$ & $\mathbf{a}_{\mathrm{Au}}{ }^{(\text {Pre. })}$ & $\begin{array}{c}\mathbf{a}_{\mathrm{Au}}{ }^{(\text {Expt. }} \\
\left.{ }^{*}\right)\end{array}$ \\
\hline 0.1 & -0.16230 & -0.17702 & 0.423 & 0.577 \\
\hline 0.2 & -0.21479 & -0.23281 & 0.611 & 0.673 \\
\hline 0.3 & -0.23933 & -0.25301 & 0.701 & 0.683 \\
\hline 0.4 & -0.25061 & -0.25345 & 0.747 & 0.693 \\
\hline 0.5 & -0.25390 & -0.23984 & 0.775 & 0.717 \\
\hline 0.6 & -0.25061 & -0.21699 & 0.799 & 0.754 \\
\hline 0.7 & -0.23933 & -0.19064 & 0.827 & 0.799 \\
\hline 0.8 & -0.21479 & -0.16253 & 0.865 & 0.848 \\
\hline 0.9 & -0.16230 & -0.12563 & 0.918 & 0.914 \\
\hline
\end{tabular}

where $a_{i, \text { exp }}$ and $a_{i, p r e}$ are the experimental data and the predicted values of component $i$ in the liquid alloys, respectively.

\section{RESULTS AND DISCUSSION}

In quasi-chemical approximation model, the interaction energy parameter $\boldsymbol{\omega}$ and the coordination number $Z=10$ $[19,25]$ are the parameters required for the computation of the thermodynamic properties of the binary liquid alloys. The parameter $\omega$ in this model is assumed to be temperature independent and it has been estimated by simultaneously fitting the experimental data of free energy of mixing and activity throughout the whole concentration range. The best fit values of the parameter $\omega$ optimized via Eqn. (4) for the six binary liquid alloys investigated at different working temperatures are listed in Table 1. These parameters remain unchanged throughout the computations. The positive value of $\omega$ ensures that the attraction between unlike atoms (A-B) is less than that of like atoms (A-A or $\mathrm{B}-\mathrm{B})$, indicating that there is a tendency of homocoordination of atoms in the binary liquid Au-Ni alloys. On the other hand, negative values of $\omega$ for binary liquid Au$\mathrm{Cu}, \mathrm{Au}-\mathrm{Zn}, \mathrm{Au}-\mathrm{Pb}, \mathrm{Au}-\mathrm{Sn}$ and Al-Au alloys imply that the attraction between unlike atoms (A-B) is more favoured than that of like atoms (A-A or B-B), thus suggesting the presence of chemical short-range order in the liquid alloys.

The results of the predicted free energy of mixing calculated using Eqn. (5) along with the experimental data are presented in Tables 2 through 7 . It is evident from the tables that the theoretical predicted values are in reasonable agreement with the experimental observation taken from Hultgren et al. [1] . Al-Au at $1338 \mathrm{~K}$ exhibits the highest tendency for compound formation and is the most interacting out of the six gold-based binary alloys studied with calculated minimum $\mathrm{G}_{\mathrm{M}}$ value of $-3.72808 \mathrm{RT}$ (in RT unit) at $\mathrm{c}_{\mathrm{Au}}=0.5$, which correlates well with experimental value of -3.72820 . This is closely followed by $\mathrm{Au}-\mathrm{Zn}$ at $1080 \mathrm{~K}, \mathrm{Au}-\mathrm{Sn}$ at $823 \mathrm{~K}, \mathrm{Au}-\mathrm{Cu}$ at $1550 \mathrm{~K}$ and $\mathrm{Au}-\mathrm{Pb}$ at $1200 \mathrm{~K}$ with calculated minimum $\mathrm{G}_{\mathrm{M}}$ values of -2.93450 RT, -2.55563 RT, -1.17620 RT and -0.99629 RT, respectively. Au-Ni at $1150 \mathrm{~K}$ in the liquid state is the least interacting alloy. The experimental values of $\frac{G_{M}}{R T}$ in Hultgren et al. [1] as given in Tables 3 and 6 when $\mathrm{c}_{\mathrm{Au}}=0.1$ (bold face), perhaps appear in non-smart form.

In Fig. $8(\mathrm{a}, \mathrm{b}, \mathrm{c})$, we present the results of the predicted free energy of mixing calculated using the QACM along with the experimental free energy of mixing data of Kostov et al. [10] obtained using the FactSage Thermochemical software to further show the suitability of the QACM in predicting thermodynamic properties for binary liquid alloys. Activity is another important thermodynamic quantity which can be obtained directly from experimental studies [18]. The interactions among the constituent components of a binary liquid system are assumed to be 
Table 6: Predicted and Experimental free energy of mixing values along with the calculated activity of $\mathrm{Au}$ in binary liquid $\mathrm{Au}-\mathrm{Sn}$ alloys at $823 \mathrm{~K}$, respectively [1]. $\left(S_{G_{M}}= \pm 0.03655\right.$, $\left.S_{a_{A u}}= \pm 0.0160\right)$

\begin{tabular}{|c|c|c|c|c|}
\hline & \multicolumn{2}{|c|}{ Au-Sn } & & \\
\hline $\mathrm{C} A \boldsymbol{u}$ & $\mathbf{G}_{\mathbf{M}} / \mathbf{R T}^{(\text {Pre. }}$ & $\mathbf{G}_{M} / \mathbf{R T}^{(\text {Expt.*) }}$ & $\mathbf{a}_{\mathrm{Au}}{ }^{(\text {Pre. })}$ & $\mathbf{a}_{\mathrm{Au}}{ }^{(\text {Expt.**) }}$ \\
\hline 0.1 & -0.92936 & -1.90949 & 0.00035 & 0.00072 \\
\hline 0.2 & -1.61799 & -1.94693 & 0.00166 & 0.00240 \\
\hline 0.3 & -2.12732 & -2.37843 & 0.00642 & 0.00650 \\
\hline 0.4 & -2.44625 & -2.57238 & 0.02315 & 0.01700 \\
\hline 0.5 & -2.55563 & -2.55151 & 0.07703 & 0.04500 \\
\hline 0.6 & -2.44625 & -2.35203 & 0.20624 & 0.10700 \\
\hline 0.7 & -2.12732 & -1.98806 & 0.41652 & 0.23400 \\
\hline 0.8 & -1.61799 & -1.48168 & 0.65702 & 0.44200 \\
\hline 0.9 & -0.92931 & -0.83966 & 0.86223 & 0.48500 \\
\hline
\end{tabular}

Table 7: Predicted and Experimental free energy of mixing values along with the calculated activity of $\mathrm{Au}$ in binary liquid $\mathrm{Al}-\mathrm{Au}$ alloys at $1338 \mathrm{~K}$, respectively [1]. $\quad\left(S_{G_{M}}= \pm 0.1984\right.$, $S_{a_{A u}}= \pm 0.0753$ )

\begin{tabular}{|c|c|c|c|c|}
\hline & \multicolumn{2}{|c|}{ Au-Sn } & & \\
\hline $\mathrm{CAu}$ & $\mathbf{G}_{\mathbf{M}} / \mathbf{R T}^{(\text {Pre. }}$ & $\mathbf{G}_{M} / \mathbf{R T}^{\left(\text {Expt. }^{*}\right)}$ & $\mathbf{a}_{\mathrm{Au}}{ }^{(\text {Pre. })}$ & $\mathbf{a}_{\mathrm{Au}}{ }^{\left(\text {Expt. }^{*}\right)}$ \\
\hline 0.1 & -1.26002 & -1.18736 & 0.00001 & 0.00003 \\
\hline 0.2 & -2.25616 & -2.11611 & 0.00008 & 0.00016 \\
\hline 0.3 & -3.03232 & -2.86401 & 0.00049 & 0.00058 \\
\hline 0.4 & -3.54501 & -3.42277 & 0.0034 & 0.0023 \\
\hline 0.5 & -3.72808 & -3.72820 & 0.0240 & 0.0116 \\
\hline 0.6 & -3.54501 & -3.70630 & 0.1213 & 0.0545 \\
\hline 0.7 & -3.03233 & -3.33367 & 0.3432 & 0.1880 \\
\hline 0.8 & -2.25616 & -2.59671 & 0.6213 & 0.4770 \\
\hline 0.9 & -1.26002 & -1.49128 & 0.8542 & 0.8100 \\
\hline
\end{tabular}

determined by the magnitude of the activities, which in turn determines the bond energies. Experimental determination of activities for a class of similar system can be expected to provide, at least, a basis for correlating the mixing behaviour, which may be useful in extrapolating the behaviour of more complex system. Using Eqn. (7), the activities of $\mathrm{Au}$ in the six gold-based binary liquid alloys were calculated. The results of the predicted activities of $\mathrm{Au}$ alongside experimental data are also given in Tables 2 through 7 . The predicted activities values correlate well with the experimental values. The activity values of $\mathrm{Au}$ in liquid $\mathrm{Au}-\mathrm{Cu}, \mathrm{Au}-\mathrm{Zn}, \mathrm{Au}-\mathrm{Pb}, \mathrm{Au}-\mathrm{Sn}$ and $\mathrm{Al}-\mathrm{Cu}$ alloys show negative deviations from ideal mixture behaviour, whereas the activity values for liquid $\mathrm{Au}-\mathrm{Ni}$ show large positive deviations from the ideal.

In addition, the deviations between the predicted and experimental values for the free energy of mixing and activities were assessed by computing the standard errors using Eqn.(8). It can be seen that the predicted average deviations when compared with the experimental data vary between $\pm 0.0072- \pm 0.3655$ for the free energy of mixing and between \pm 0.0145 to \pm 0.1984 for the activity. The relatively small deviations observed between the calculated and experimental values thus show that the quasi-chemical approximation model may be an alternative method for predicting the thermodynamic properties of binary liquid alloys. The model is quite efficient and reliable because it has a physical meaning from the viewpoint of statistical thermodynamics.

\section{Conclusion}

The quasi-chemical approximation model which is based on statistical thermodynamics has been employed to predict the thermodynamic properties of some binary liquid alloys. The predicted results of the free energy of mixing and activities of $\mathrm{Au}$ in the selected Au-based binary liquid alloys have been compared with experimental values. It is found that the predicted values with the model are in good agreement with those of experimental data; thus, indicating that the model is reliable, efficient and cost effective with a good physical basis.

\section{REFERENCES}

[1] Hultgren R., Desai P.D., Hawkins D.T., Gleiser M., Kelly K.K. (1973). Selected values of the thermodynamic properties of binary alloys, American Society of Metals, Ohio.

[2] Mikula A. (1992). Thermodynamic properties in the liquid Ag-Sb-Zn system. Metallurgical Transactions B, Vol. 23B, 601-611.

[3] Katayama I., Nakayama J.I., Ikura T., Tanaka T., Kozuka Z. and Iida T. (1993). Measurement of activity of gallium in Ga-Sb-In alloys by EMF method using zirconia as solid electrolyte. Journal of Non-Crystalline Solids, 156158, 393-397.

[4] Katayama I., Fukuda1 Y., Hattori Y. and Maruyama T. (1998). Measurement of activity of gallium in liquid Ga-Sb-Sn alloys by EMF method with zirconia as solid electrolyte. Thermochimica Acta, 314,175-181.

[5] Katayama I., Shimazawa K., Zivkovic D., Manasijevic D., Zivkovic Z. and Iida T.(2003). Activity measurements of $\mathrm{Ga}$ in liquid $\mathrm{Ga}-\mathrm{Tl}$ alloys by EMF method with zirconia solid electrolyte. Z. Metallkde 94, 14.

[6] Hindler M., Guo Z. and Mikula A. (2012. Leadfree solder alloys: Thermodynamic properties of the $\mathrm{Au}+$ $\mathrm{Sb}+\mathrm{Sn})$ and the $(\mathrm{Au}+\mathrm{Sb})$ system. Journal of chemical thermodynamics, 55, 102-109.

[7] Behera C.K. and Sonaye A. (2013). Measurement of zinc activity in the ternary In- $\mathrm{Zn} \mathrm{Sn}$ alloys by EMF method. Thermochimica Acta 568, 196-203. 
Table 8: Predicted and Experimental free energy of mixing values of binary liquid Ti-Si alloys at $2000 \mathrm{~K}, 2400 \mathrm{~K}$ and 2473 $\mathrm{K}$, respectively [1]. ( $\left.S_{G_{M}}= \pm 0.1984, S_{a_{A u}}= \pm 0.0753\right)$ (a) Ti-Si at $2000 \mathrm{~K}\left([11], S_{G_{M}}= \pm 0.2121\right)$

\begin{tabular}{|l|l|l|}
\hline $\mathbf{C} A \boldsymbol{u}$ & $\mathbf{G M}_{\mathbf{M}} / \mathbf{R T}^{\text {(Pre.) }}$ & $\left.\mathbf{G M}_{\mathbf{M}} / \mathbf{R T}^{\text {(Expt. }}{ }^{*}\right)$ \\
\hline 0.1 & -1.22218 & -1.12485 \\
\hline 0.2 & -2.18251 & -2.08932 \\
\hline 0.3 & -2.92670 & -2.90267 \\
\hline 0.4 & -3.41520 & -3.49568 \\
\hline 0.5 & -3.58872 & -3.79329 \\
\hline 0.6 & -3.41520 & -3.73514 \\
\hline 0.7 & -2.9267 & -3.29109 \\
\hline 0.8 & -2.18251 & -2.47468 \\
\hline 0.9 & -1.22218 & -1.35247 \\
\hline
\end{tabular}

(b) Ti-Si at $2400 \mathrm{~K}\left([11], S_{G_{M}}= \pm 0.2214\right)$

\begin{tabular}{|l|l|l|}
\hline $\mathbf{C} \boldsymbol{A} \boldsymbol{u}$ & $\mathbf{G M}_{\mathbf{M}} / \mathbf{R T}^{\text {(Pre.) }}$ & $\mathbf{G M}_{\mathbf{M}} / \mathbf{R T}^{\text {(Expt. }^{*} \text { ) }}$ \\
\hline 0.1 & -1.04297 & -0.96900 \\
\hline 0.2 & -1.83572 & -1.78450 \\
\hline 0.3 & -2.43373 & -2.46820 \\
\hline 0.4 & -2.81439 & -2.96513 \\
\hline 0.5 & -2.94671 & -3.21420 \\
\hline 0.6 & -2.81439 & -3.16469 \\
\hline 0.7 & -2.43337 & -2.79174 \\
\hline 0.8 & -1.83572 & -2.10558 \\
\hline 0.9 & -1.04297 & -1.15868 \\
\hline
\end{tabular}

(b) Ti-Si at $2473 \mathrm{~K}\left([11], S_{G_{M}}= \pm 0.1844\right)$

\begin{tabular}{|l|l|l|}
\hline $\mathbf{C} \boldsymbol{A} \boldsymbol{u}$ & $\mathbf{G}_{\mathbf{M}} / \mathbf{R T}^{\text {(Pre.) }}$ & $\mathbf{G}_{\mathbf{M}} / \mathbf{R T}^{\text {(Expt.*) }}$ \\
\hline 0.1 & -1.03562 & -0.94599 \\
\hline 0.2 & -1.82159 & -1.73941 \\
\hline 0.3 & -2.41341 & -2.40395 \\
\hline 0.4 & -2.79028 & -2.88680 \\
\hline 0.5 & -2.92103 & -3.12851 \\
\hline 0.6 & -2.79028 & -3.08051 \\
\hline 0.7 & -2.41341 & -2.71808 \\
\hline 0.8 & -1.82159 & -2.05111 \\
\hline 0.9 & -1.03562 & -1.13007 \\
\hline
\end{tabular}

[8] Chou K.C. (1990). A new treatment for calculating activities from phase-diagrams containing solid-solution. Calphad 14(3), 275-282.

[9] Tao D. P. (2003). Prediction of the thermodynamic properties of binary continuous solutions by infinite dilute activity coefficients. Thermochimica Acta 408, 67-74.

[10] Kostov A., Zivkovic D. and Freidrich B. (2007). Thermodynamic predicting of $\mathrm{Si}-\mathrm{Me}(\mathrm{Me}=\mathrm{Ti}, \mathrm{Al})$ binary systems. Journal of Mining and Metallurgy 43B, p29-38.

[11] Kostov A., Freidrich B. and Zivkovic D. (2008) Thermodynamic calculations in alloys Ti-Al, Ti-Fe, Al-Fe and Ti-Al-Fe. Journal of Mining and Metallurgy 44B, p4961.
[12] Odusote Y. A., Popoola I.A. and Oluyamo S.S. (2016). Bulk and surface properties of demixing liquid AlSn and Sn-Tl alloys. Applied Physics A Vol. 122(2), pp.19.

[13] Hildebrand J.H. and Scott R.L. (1950). The solubility of Nonelectrolytes, $3^{\text {rd }}$ edition, Van Northland Reinhold, New York, N. Y.

[14] Lupis C.H.P. and Elliot J.F. (1967). Prediction of enthalpy and entropy interaction coefficients by the central atoms theory. Acta Metallurgica 15(2), 265-276.

[15] Tao D. P., Yang B. and Li D. F. (2002). Prediction of the thermodynamic properties of quinary liquid alloys by modified coordination equation. Fluid Phase Equilibria 193, 167-177.

[16] De boer F.R., Boom R., Mattens W.C.M., Miedema A. R. and Niessen A. R. (1988). Cohesion in Metals (Elsevier Science Publishers, North-Holland, Amsterdam).

[17] Bakker, H. (1998). Enthalpies in alloys: Miedema's Semi-Empirical Model (Trans Technol. Pub. Inc., Switzland) .

[18] Singh R.N. and March N.H. (1995) in: Intermetallic Compounds, Principles and Practice, Vol. 1, J.H. Westbrook, R.L. Fleischer, (Eds.), Wiley, New York. p.661.

[19] Anusionwu B.C. and Adebayo G.A. (2001). Quasi-chemical studies of ordering in the $\mathrm{Cu}-\mathrm{Zr}$ and $\mathrm{Cu}-\mathrm{Si}$ melts, Journal of Alloys and Compound, 329, p. 162-167.

[20] Novakovic R. and Zivkovic D. (2005). Thermodynamics and surface properties of liquid Ga-X (X $=\mathrm{Sn}, \mathrm{Zn}$ ) alloys, Journal of Material Science 40, p.22512257.

[21] Anusionwu B.C. (2006). Thermodynamic and surface properties of $\mathrm{Sb}-\mathrm{Sn}$ and $\mathrm{In}-\mathrm{Sn}$ liquid alloys. Pramana Journal of Physics, Vol. 67(2) 319-330.

[22] Odusote Y. A., Fayose O. O. and Odigie P. J. (2007). Mixing Properties of $\mathrm{X}-\mathrm{Pb},(\mathrm{X}=\mathrm{Cd}$, In) Liquid Binary Alloys. Journal of Non-Crystalline Solids Vol., 353, No. 52-54, 4666-4671.

[23] Odusote Y.A., Awe O.E. and Akinto O.F. (2014). Thermodynamic study of homo pairs in molten Cd-Me, $(\mathrm{Me}=\mathrm{Ga}, \mathrm{In})$ binary systems. Journal of the Nigerian Association of Mathematical Physics Vol. 26, pp. 187-194. [24] Singh R.N. and Sommer F., Segregation and immiscibility in liquid binary alloys, Report Progress in Physics 60 (1997) p.57.

[25] Odusote Y.A., Hussain L.A. and Awe E.O. (2007). Bulk and dynamic properties in Al-Zn and Bi-In liquid alloys using a theoretical model. Journal of NonCrystalline Solids, 353, 1167-1171.

[26] Kong L.X., Yang B., Xu B.Q., Li Y.F and Liu D.C. (2014). Application of MIVM for Pb-Sn-Sb ternary system in vacuum. Vacuum 101, 324-327.

[27] Goodman D.W. (2004). Catalysis by supported gold nanoclusters. Dekker Encyclopedia of Nano science and Nanotechnology, 611-620.

[28] Mahladisa M.A., Ackermann L. and Ngoepe P.E. (2005). Structural properties of gold clusters at different 
temperatures. South African Journal of Sciences, 101, 471474.

[29] Soler J.M., Garzon I.L. and Joannopoulos J.D. (2001). Structural patterns of unsupported gold clusters. Solids State Communication, 117, 621-62.

[30] Prasad L.C., Singh R.N., Singh V.N. and Singh G.P. (1998). Correlation between bulk and surface properties of AgSn liquid alloys, Journal of Physics
Chemistry B, 102, p.921-926.

[31] Prasad L.C. and Singh R.N. (1990). A QuasiLattice Model for the thermodynamic properties of $\mathrm{Au}-\mathrm{Zn}$ liquid alloys, Physics and Chemistry of Liquid, Vol. 22, No. 1-2, p.1-9.

[32] Singh R.N. (1987). Short-range order and concentration fluctuations in binary molten alloys, Canadian Journal of Physics, Vol. 65, No. 3, p.309-325. 